\title{
Optimizing the void
}

\section{Richard W. Norman, MD, FRCSC}

Department of Urology, Dalhousie University, Halifax, NS
Cite as: Can Urol Assoc J 2012;6(1):34-5. http://dx.doi.org/10.5489/cuaj.12010

$P$ atients do not enjoy performing 24-hour urine collections. Some dream up elaborate excuses as to why they have been unable to provide the samples. A couple of the more interesting ones include: "The caps came off the bottles and both spilled in the trunk of my car on the way to the lab" and "My wife thought it was a bottle of a new generic windshield washer fluid and put it in the car." Despite this resistance, most patients carry out 24-hour voids successfully, following oral and written instructions as emphasized in the accompanying paper. ${ }^{1}$ The information gained can be very useful in identifying abnormalities in specific urinary risk factors for targeted fluid, dietary and/or pharmacologic intervention.

The accompanying article addresses one of the many long-term controversies regarding these collections (i.e., the benefits of two consecutive compared with a single 24-hour urine collection done on a free diet). ${ }^{1}$ The authors concluded that two collections yielded a greater likelihood of identifying an abnormality in one or more of the measured parameters such that clinical decision-making would change in almost $50 \%$ of patients. ${ }^{1}$ Others have suggested that the optimal number is 3 to 6 collections. ${ }^{2,3}$ I suspect more information could be gleaned from a larger number of collections, but from a practical and cost-effective point of view, I agree with the choice of two.

Many urologists have different opinions as to which stone formers should perform 24-hour urine collections. Some believe these tests are indicated only in patients with complex stone disease, ${ }^{4}$ others offer them to all stone formers because almost all are keen to explore investigations to identify strategies to reduce the risk of recurrences. ${ }^{5}$ Single and recurrent stone formers have been shown to have simi- lar abnormalities. ${ }^{6}$ The current study looked at all patients referred to a tertiary care stone clinic and did not differentiate between these groups. ${ }^{1}$ I propose that all recurrent stone formers start off as single stone formers and I support all of these patients doing the collections.

It is important to wait at least three months following an episode of renal colic and/or surgical intervention for stones before collecting 24-hour voids to obtain the most useful results. Performing these collections earlier leads to an artificially low assessment of risk due to higher urine volumes and lower calcium excretion during this timeframe. ${ }^{7}$

Occupational environment can also affect the propensity to form renal stones. Furthermore, many working patients have different patterns of fluid intake, dietary habits and physical activity during the week compared with the weekend. These disparities can lead to profound effects on the results of 24-hour voids in some patients and I try to arrange for one to be done on a working day and one on a weekend day.

My philosophy has been to start intervention with fluid and dietary modification and to reserve drug intervention for those patients who do not comply with or fail to respond to lifestyle adjustments. I have found it very useful to have self-reported written dietary histories done in conjunction with the 24-hour urine collections. In doing so, individual dietary habits can be identified and targeted by our stone clinic dietician to improve abnormal urinary risk factors relevant to the type of stone.

One of the most important aspects of these 24-hour voids is that they produce baseline data that can be used as a reference and teaching tool for patients and their families. Follow-up measurements, 6 to 12 months later, in conjunction with appropriate imaging, when appropriate, can provide a vigorous assessment of the improvements, in conjunction with stone recurrence and/or growth, due to recommended fluid intake, dietary moderation and pharmacologic therapy.

In summary, there are numerous variables which have 
to be considered to optimize the information obtained from 24-hour voids so that effective strategies for reduced urine supersaturation can be implemented.

Competing interests: None declared.

This paper has been peer-reviewed.

\section{References}

1. Nayan M, Elkoushy MA, Andonian S. Variations between two 24-hour urine collections in patients presenting to a tertiary stone clinic. Can Urol Assoc J 2012; 6 (1):30-3. http://dx.doi.org/10.5489/cuaj.11131
2. Coe FL, Parks JH. Nephrolithiasis: Pathogenesis and Treatment. 2nd ed. Chicago: Year Book Medical Publishers; 1988:31.

3. Marshall VR. The simple investigation and medical treatment of renal calculi. Aust Prescr 1996;19:94-7.

4. Patterson R, Fernandez A, Razvi $\mathrm{H}$, et al. Evaluation and medical management of the kidney stone patient. Can Urol Assoc J 2010;4:375-9.

5. Grampsas SA, Moore M, Chandhoke PS. 10-year experience with extracorporeal shockwave lithotripsy in the state of Colorado. J Endourol 2000;14:711-4. http://dx.doi.org/10.1089/end.2000.14.711

6. Pak CY. Should patients with single renal stone occurrence undergo diagnostic evaluation? I Urol 1982; 127:855-8

7. Norman RW, Bath SS, Robertson WG, et al. When should patients with symptomatic urinary stone disease be evaluated metabolically? J Urol 1984;132:1137-9.

Correspondence: Dr. Richard W. Norman, Professor of Urology, Department of Urology, Dalhousie University, 5991 Spring Garden Rd., Suite 620, Halifax, NS B3H 1Y6; fax: 902-422-0033; richard.norman@dal.ca 